\title{
Mulheres convivendo com endometriose: percepções sobre a doença
}

\author{
Women living with endometriosis: perceptions of disease
}

Érica Luiza de Abreu Ramos ${ }^{a}$, Vanessa Moreira da Silva Soeiro ${ }^{b}$, Cláudia Teresa Frias Riosc

a Enfermeira graduada pela Universidade Federal do Maranhão.

${ }^{\text {b} E n f e r m e i r a . ~ D o u t o r a n d a ~ e m ~ S a u ́ d e ~ C o l e t i v a . ~ U n i v e r s i d a d e ~ F e d e r a l ~ d o ~ M a r a n h a ̃ o . ~}$

'Enfermeira. Doutora em Saúde Coletiva. Universidade Federal do Maranhão

\begin{tabular}{l|l} 
RESUMO Objetivos: Identificar o conhecimento de mulheres que convivem com endometriose a respeito da doença e
\end{tabular} ponderar suas percepções sobre a qualidade de vida pós-diagnóstico.

Materiais e Métodos: Estudo exploratório, descritivo, qualitativo, realizado no Setor de Dor Pélvica e Endometriose do Serviço de Obstetrícia e Ginecologia de um hospital universitário. Participaram da pesquisa 13 mulheres com idade entre 18 e 46 anos.

Resultados: A maioria das mulheres pertencia à faixa etária entre 30 a 39 anos, com tempo de doença entre 1 a 4 anos, pertencentes à média classe-média, em uso de método contraceptivo, sem diagnóstico de infertilidade, com ciclo menstrual irregular e com histórico pregresso de gravidez (a maioria com abortos). As participantes da pesquisa não conhecem a doença que lhes aflige, vivem em companhia da dor e da possível infertilidade.

Conclusões: As mulheres incluídas nesta pesquisa, em sua maioria, não conhecem a doença com a qual convivem e percebem as mudanças advindas da doença de forma negativa.

Palavras-chave: endometriose; assistência integral à saúde; saúde da mulher.

Objectives: To identify the knowledge of women living with endometriosis regarding the disease and to ponder their perceptions about post-diagnosis quality of life.

Materials and Methods: An exploratory, descriptive, qualitative study was performed in the Pelvic Pain and Endometriosis Department of the Obstetrics and Gynecology Service of an university hospital. Thirteen women between the ages of 18 and 46 participated in the study.

Results: The majority of the women belonged to the age group between 30 and 39 years, with a disease period between 1 and 4 years old, belonging to the middle class, using a contraceptive method, with no diagnosis of infertility, with irregular menstrual cycles and with history of pregnancy (most with abortions). The participants of the research do not know the disease that affects them. They live in the company of pain and the possible infertility.

Conclusion: The women included in this research, for the most part, do not know the disease with which they coexist and perceive the changes coming from the disease in a negative way.

Keywords: endometriosis; comprehensive health care; women's health.

\section{Correspondência:}

VANESSA MOREIRA DA SILVA SOEIRO

Travessa Santo Antônio, casa 9-C - Bairro Santo Antônio

65046-590 São Luís, MA, Brasil

E-mail: moreira.vanessa@hotmail.com 


\section{INTRODUÇÃO}

A endometriose é uma patologia ginecológica progressiva caracterizada pela presença de tecido endometrial de caráter benigno fora da cavidade uterina, ou seja, quando o endométrio descama e não segue seu curso natural de ser eliminado através do canal vaginal, ele implanta-se em outras áreas do corpo humano, formando um tecido fibrótico chamado de aderência. Geralmente acomete mulheres em idade reprodutiva, desde a puberdade até a menopausa, causando lesões no aparelho reprodutor e, consequentemente, o aparecimento de manifestações dolorosas e, em alguns casos, infertilidade ${ }^{1,2}$.

Cerca de dois terços das mulheres com endometriose estão sofrendo de dor pélvica crônica, e 30-40\% delas estão experimentando infertilidade. Diz-se que a prevalência de infertilidade em mulheres afetadas pela endometriose é 20 vezes maior do que aquelas sem essa condição ${ }^{3}$. Ainda que não exista uma etiopatogenia concreta da doença, suficiente para estabelecer seus fatores de risco, a maioria das portadoras é da raça branca, nulíparas, normolíneas, ansiosas, de alto poder aquisitivo, com grau de instrução elevado, que retardam o casamento e a concepção e que relatam história prévia de dor pélvica ${ }^{4,5}$. A taxa de prevalência de endometriose na população geral é desconhecida, porque o diagnóstico definitivo da condição é possível por cirurgia laparoscópica, portanto, muitos casos não são reconhecidos. No entanto, vários estudos relataram uma prevalência de $2-15 \%$ de endometriose entre as idades reprodutivas ${ }^{6,7,8}$. Além disso, estudos mostraram que 30 a $45 \%$ das mulheres com infertilidade ou dor sofrem de endometriose ${ }^{8}$.

Os tratamentos propostos para a endometriose buscam controlar os sintomas, neutralizar as causas, remover focos e lesões e restabelecer a fertilidade. As medidas para o tratamento incluem: farmacológicas (anti-inflamatórios não esteroides - AINE), hormonais (como progestogênios, sistema intrauterino liberador de levonorgestrel, anticoncepcionais orais, análogos do hormônio liberador das gonadotrofinas, letrozole, danazol e gestrinona) e intervenções cirúrgicas. Algumas terapias integrativas têm sido recomendadas para o alívio da sintomatologia, dentre elas: acupuntura, homeopatia, estimulação elétrica nervosa, terapia nutricional, massagem, yoga, pilates e exercícios aeróbicos ${ }^{9}$.

A falta de conhecimento das mulheres sobre a doença é uma das principais barreiras para a detecção precoce do problema, cujo prognóstico é melhor se descoberto no início. Estima-se que no Brasil, 55\% das mulheres acometidas pela endometriose não sabem o que é a doença e $66 \%$ delas não conseguem identificar a que essa patologia tipicamente feminina está associada ${ }^{10}$. Ajudar a paciente a compreender a patologia, esclarecer medicações e efeitos e dar a ela uma atenção mais individualizada são fundamentais para o tratamento ${ }^{11}$.

Os sintomas dolorosos crônicos da endometriose e suas consequências negativas também podem reduzir severamente a qualidade de vida das mulheres afetadas. Estudos qualitativos documentaram os impactos negativos desta doença na vida diária; bem-estar físico, mental e social; saúde geral; interações interpessoais; produtividade e autoestima ${ }^{7,8,12}$. A endometriose afeta diferentes aspectos da vida das mulheres em idade reprodutiva. Em uma metanálise, utilizando 7 estudos, cujo objetivo foi investigar o efeito da endometriose na qualidade de vida (QV) dos pacientes afetados $(n=1619)$ observou-se que essa patologia possui considerável carga negativa na $\mathrm{QV}^{3}$.

Entender como as pacientes convivem com a endometriose e o que conhecem sobre essa patologia parece ser o início para se desenvolver um tratamento integral, dando subsídio para futuras intervenções. Acredita-se que a endometriose interfere substancialmente no universo feminino, tanto no ponto de vista físico quanto no psicológico, acarretando, por vezes, quadro de depressão. Partindo desse princípio, este estudo pretendeu responder ao seguinte questionamento: $\mathrm{O}$ que as mulheres que convivem com endometriose conhecem acerca da doença e como esta influencia na sua percepção de qualidade de vida?

Este estudo tem por objetivo identificar o conhecimento de mulheres que convivem com endometriose a respeito da doença e ponderar acerca de suas percepções sobre a qualidade de vida pós-diagnóstico.

\section{MATERIAIS E MÉTODOS}

Estudo descritivo de abordagem qualitativa, realizado no Setor de Dor Pélvica e Endometriose do Serviço de Obstetrícia e Ginecologia do Hospital Universitário Materno Infantil da Universidade Federal do Maranhão, uma instituição que faz parte da Rede de Atendimento à Mulher, situada em São Luís-MA, Brasil.

Utilizou-se amostra por conveniência, sendo um total de 13 mulheres (tamanho amostral definido em virtude da reincidência de informações ou saturação dos dados, situação ocorrida quando nenhuma informação nova é acrescentada com a continuidade do processo de pesquisa), em idade reprodutiva, que aguardavam consulta no referido setor, nos meses de novembro e dezembro de 2013.

O instrumento de coleta de dados foi entrevista semiestruturada, constituída de 4 perguntas voltadas para 
o conhecimento e sentimentos das mesmas em relação à doença. Coletaram-se ainda dados referentes à idade, tempo da doença (desde o diagnóstico), renda, antecedentes ginecológicos e obstétricos. A técnica utilizada na análise de dados foi a Análise de Conteúdo de Bardin ${ }^{13}$. Durante a análise e interpretação desses dados coletados e transcritos, foram atribuídos às participantes nomes fictícios (de flores), preservando a fim de se preservar o anonimato.

As participantes foram esclarecidas quanto aos objetivos e a metodologia do estudo, sendo solicitada a assinatura do Termo de Consentimento Livre e Esclarecido assegurando-se o direito de acesso aos dados, à autonomia de decidir não mais participar da pesquisa, bem como o esclarecimento dos riscos e benefícios da participação no estudo.

Esta pesquisa possui aprovação do Comitê de Ética em Pesquisa do Hospital Universitário da Universidade Federal do Maranhão, conforme o parecer no 428.641, de 18 de outubro de 2013. Em cumprimento à Resolução 466/12 do Conselho Nacional de Saúde e suas complementares, que regulamentam a pesquisa em seres humanos, em vigor no país, garantiu-se o sigilo da identidade dos participantes da pesquisa, bem como ausência de qualquer ônus para o entrevistado.

\section{RESULTADOS E DISCUSSÃO}

\section{Caracterização das mulheres acometidas por endometriose}

A caracterização das pacientes se tornou necessária, pois tais características influem direta ou indiretamente na percepção destas mulheres a respeito da patologia.

Conforme a Tabela 1, a maioria das mulheres entrevistadas encontra-se na faixa etária entre 30 a 39 anos, correspondendo a $61,54 \%(n=8)$ do total. Seguida pelo grupo com idade entre 40 a 49 anos $(23,08 \% ; n=3)$. Deste modo, conjectura-se ter havido significativa demora no diagnóstico e no início do tratamento. Hoje, esforços no ramo da medicina estão sendo feitos para que esse tempo reduza. Os achados de nossa pesquisa assemelham-se aos de outros estudos em que se constatou que a endometriose é quase que exclusividade da mulher no seu período reprodutivo ${ }^{3,6}$. A endometriose, por ser uma doença enigmática, seu diagnóstico é difícil e demanda considerável tempo, deste modo, as mulheres sofrem durante anos, na tentativa de descobrir o que se passa em seu corpo, o porquê de tantas dores e padecimento. No que tange à renda, a maioria destas mulheres $(69,23 \% ; n=9)$ encontra-se na média classe média. A literatura afirma que possuir maior renda permite acesso a medicações mais eficientes e acesso a tratamento médico, permitindo prognóstico favorável ${ }^{14}$.
$\mathrm{Na}$ investigação dos antecedentes ginecológicos, as participantes desta pesquisa foram questionadas quanto ao uso de métodos anticoncepcionais; presença de infertilidade ou esterilidade; e regularidade do ciclo menstrual. A maioria usa métodos contraceptivos e não apresenta infertilidade ou esterilidade $(n=9)$. Do grupo que faz uso de métodos contraceptivos, 33,33\% ( $n=3)$ fazem uso de contraceptivo oral e $66,67 \%(n=6)$ de injetável. Das quatro mulheres que referiram infertilidade ou esterilidade, $50 \%(n=2)$ realizaram o procedimento de laqueadura.

Ainda não há um tratamento adequado em virtude da falta de conhecimento a respeito da etiologia e da fisiologia da endometriose. Entretanto, visando amenizar os sintomas, terapias hormonais (orais e injetáveis) têm sido largamente utilizadas e em último caso o processo de laqueadura. O tratamento adequado dependerá exclusivamente da reação da paciente diante das opções apresentadas por seu médico ${ }^{11}$.

Tabela 1. Classificação das mulheres acometidas por endometriose segundo a faixa etária, renda, antecedentes ginecológicos e período de doença aproximado.

\begin{tabular}{|c|c|c|}
\hline Características & $\mathbf{n}$ & $\%$ \\
\hline \multicolumn{3}{|l|}{ Faixa etária } \\
\hline 15 a 19 anos & 1 & 7,69 \\
\hline 20 a 29 anos & 1 & 7,69 \\
\hline 30 a 39 anos & 8 & 61,54 \\
\hline 40 a 49 anos & 3 & 23,08 \\
\hline \multicolumn{3}{|l|}{ Renda } \\
\hline Baixa Classe Média & 3 & 23,08 \\
\hline Média Classe Média & 9 & 69,23 \\
\hline Alta Classe Média & 1 & 7,69 \\
\hline \multicolumn{3}{|c|}{ Antecedentes Ginecológicos } \\
\hline \multicolumn{3}{|c|}{ Uso de Método Contraceptivo } \\
\hline Sim & 9 & 69,27 \\
\hline Oral & 3 & 33,33 \\
\hline Injetável & 6 & 66,67 \\
\hline Não & 4 & 30,73 \\
\hline \multicolumn{3}{|c|}{ Infertilidade ou Esterilidade } \\
\hline Sim & 4 & 30,77 \\
\hline Não & 9 & 69,23 \\
\hline \multicolumn{3}{|l|}{ Ciclo Menstrual } \\
\hline Regular & 5 & 38,46 \\
\hline Irregular & 6 & 46,16 \\
\hline Ausente & 2 & 15,38 \\
\hline \multicolumn{3}{|l|}{ Período de doença* } \\
\hline$<$ que 1 ano & 2 & 15,39 \\
\hline 1 a 4 anos & 8 & 61,54 \\
\hline 5 a 9 anos & 1 & 7,69 \\
\hline 10 anos & 1 & 7,69 \\
\hline Não sabe relatar & 1 & 7,69 \\
\hline Total & 13 & 100 \\
\hline
\end{tabular}

* Segundo ano de diagnóstico. 
No que concerne ao ciclo menstrual, seis mulheres $(46,16 \%)$ relataram apresentar ciclo irregular, muitas afirmaram que antes da doença seus ciclos eram rigorosamente regulares. Apenas duas mulheres (15,38\%) não se encaixaram nesse padrão. Ambas relataram que o uso constante de medicamentos contraceptivos interrompeu a menstruação. Ciclos irregulares são características de pacientes com endometriose, isso se deve ao fato de que a frequência e o volume do fluxo aumentados podem estar relacionados a níveis elevados do estradiol e à presença maior de menstruação retrógrada ${ }^{15}$.

A maioria das mulheres $(n=8)$ teve seus diagnósticos estabelecidos no período de 1 a 4 anos, seguido por aquelas com período de doença menor que 1 ano (15,39\%). Esses achados podem estar diretamente relacionados ao aumento da divulgação da doença pela mídia e pela área da saúde. As mulheres têm maior facilidade para associar seus sintomas à doença e buscar um diagnóstico cada vez mais precoce, diminuindo o tempo de angústia pré-diagnóstico. Entretanto, isso ainda está longe do ideal. Em pesquisa realizada em São Paulo chegou-se à conclusão de que o tempo médio do diagnóstico da endometriose é em média de 3,84 anos ${ }^{16}$.

No tocante aos antecedentes obstétricos, mais especificamente nos itens "número de gestações; número de partos; e número de abortos", seis mulheres $(46,15 \%)$ não tinham histórico de gestação, sendo que 4 destas encontravam-se com a idade acima de 30 anos. Das sete $(53,84 \%)$ pacientes restantes que já tiveram gestações, apenas $15,18 \%(n=2)$ não sofreram nenhum aborto. Das cinco mulheres que referiram gestações, $23,07 \%(n=3)$ tiveram filhos e um aborto, $7,69 \%(n=1)$ tiveram filhos e dois abortos e $7,69 \%(n=1)$ não pariu nenhum filho, sofrendo três abortos. Durante a pesquisa, todas as mulheres referiram nunca ter tido um natimorto.

A endometriose gera fibrose, conhecida também como aderência, que pode encobrir os ovários ou as trompas, a ponto de impedir a liberação do óvulo na cavidade abdominal ${ }^{18}$. Sabe-se que esta patologia está presente em 10 a $22 \%$ das mulheres férteis e em 20 a $25 \%$ da população feminina infértil. Quanto às mulheres com diagnóstico de endometriose, a prevalência de infertilidade pode chegar a $60 \%{ }^{2,18}$.

\section{Conhecimento das mulheres acometidas por endometriose sobre a doença}

Nesta categoria buscou-se ponderar sobre o conhecimento que as mulheres que convivem com a endometriose têm acerca da doença que Ihes aflige, bem com suscitar a importância do profissional de saúde na educação em saúde sobre a doença.
Segundo a Constituição Federal do Brasil de 1988 ${ }^{19}$ :

Art. 196. A saúde é direito de todos e dever do Estado, garantido mediante políticas sociais e econômicas que visem à redução do risco de doença e de outros agravos e ao acesso universal e igualitário às ações e serviços para sua promoção, proteção e recuperação.

De acordo com a Lei Orgânica da Saúde (Lei no 8.080/90), Capítulo II, Dos Princípios e Diretrizes ${ }^{20}$ :

Art. 70 As ações e serviços públicos de saúde e os serviços privados contratados ou conveniados que integram o Sistema Único de Saúde (SUS), são desenvolvidos de acordo com as diretrizes previstas no art. 198 da Constituição Federal, obedecendo ainda aos seguintes princípios: (...) $\vee$ - direito à informação, às pessoas assistidas, sobre sua saúde.

Partindo desse pressuposto, é correto afirmar que todo e qualquer indivíduo tem o direito de ser informado sobre a doença que lhe afeta, o motivo e a metodologia utilizada em cada procedimento ao qual é submetido, ou qualquer outro fato que possa lhe causar futuramente indícios de sofrimento físico e/ou psíquico ${ }^{21}$.

Uma contradição a este regulamento se evidenciou durante as entrevistas realizadas. Ao serem indagadas a respeito do conhecimento referente à doença que lhes afligia a maioria das mulheres não soube elaborar um conceito que se aproximasse do real significado da endometriose. Sem saber o que responder a tal pergunta, as mulheres associavam a doença aos seus sintomas, relatavam a história de como a mesma se manifestou e os empecilhos que tiveram que enfrentar. Como fizeram Begônia e Orquídea, demonstrando total desconhecimento a respeito do assunto:

"Pra te falar a verdade eu não sei, dizem que é uma inflamação, eu não sei explicar direito, só sei que dói demais. O que eu sei a respeito é devido ao que eu sinto. As dores, porque eu sinto muitas dores. Sinto dor na costa e me sinto as vezes com febre. Incho muito... Não tenho vontade de levantar, se eu pudesse ficava o dia deitada." (Begônia)

"É que dói. É muita dor. Eu não sei bem o que é, porque...eu sei que eu sinto muita dor na vagina, no útero. Me dói demais e a médica disse que era isso aí." (Orquídea)

Houve ainda mulheres que alegaram ter seu direito de conhecimento à sua saúde negado e demonstraram verdadeira revolta para com os profissionais que lhes atenderam anteriormente, mas que apesar disso sabiam do 
que se tratava, por terem buscado outro meio de informação. Conforme relatado por Gardênia:

\begin{abstract}
"Eu conheço muito pouco, minha primeira ginecologista, que ficou comigo mais de 3 anos, nunca quis me dizer o que eu tinha de verdade. Depois de vários anos foi que eu fiquei sabendo que eu estava com endometriose. O que sei é que é um canal do sangramento, que fica procurando paredes no útero, em vez de descer pelo canal, fica procurando lugares na parede." (Gardênia)
\end{abstract}

Faz parte da função de qualquer profissional de saúde, independente da profissão ou área que atua, proporcionar a cada paciente e/ou sua família todas as informações pertinentes ao seu diagnóstico, tratamento e prognóstico. Muitos, segundo as entrevistadas, ao longo das consultas, não exerceram esse papel, não garantindo a elas um direito instituído por lei ${ }^{21}$.

Diante da falta de informação prestada pelos profissionais e pela curiosidade a respeito da endometriose, mulheres como Girassol e Íris buscaram esclarecer suas dúvidas através da mídia televisiva e da internet.

"Bom eu... fiquei sabendo através da televisão... Eu soube que a endometriose se estabiliza por uma deficiência hormonal do ciclo menstrual. E que através disso pode se formar uma pequena cobertura. Mais ou menos isso." (Girassol).

"Desde que eu desconfiei que eu pudesse ter, que eu assisti reportagem na televisão falando sobre essa doença, os sintomas eram bem parecidos com os meus, comecei a ter interesse. A ler, pesquisar, saber o que estava acontecendo... é endometriose por causa do endométrio, que descama quando a gente menstrua, e aí ele vai se acumulando e causa muita inflamação, aderências." (Íris)

A falta de conhecimento alusivo à doença, diagnóstico e tratamento por parte das pacientes têm consequências que afetam diretamente a qualidade de vida dessas mulheres, tais como: a frustração ao se deparar com os inúmeros obstáculos a serem ultrapassados; a ilusão da cura ou de concepção de filhos diante de uma doença crônica que poderá causar infertilidade; hostilidade em relação ao médico, já que o mesmo não apresenta uma solução definitiva; além do possível abandono de tratamento, visto que é ignorado que este é o responsável pelo alívio da dor e manutenção de estabilidade da doença ${ }^{21,22}$.

Faz-se necessária a realização de ações em saúde que favoreçam a autonomia, conhecimento e empoderamento das mulheres sobre a patologia, bem como estratégias que contribuam com sua qualidade de vida e com a minimização do sofrimento ocasionado pelos sintomas da endometriose. A literatura aponta que a falta de conhecimento sobre a doença implica na perda da autonomia, traz consequências sobre a tomada de decisão e adesão ao tratamento estabelecido e destaca as práticas alternativas/terapêuticas (florais de bach, heiki, acupuntura massoterapia, dança e arte terapia) como contribuintes para a melhoria da qualidade de vida dessas mulheres ${ }^{23}$.

\section{Vivência da endometriose: vida que não é mais a mesma}

Aprender a conviver com as dores pélvicas intensas, provenientes da endometriose, e ainda ter que lidar com os limites dos profissionais e do sistema de saúde pública compõem uma verdadeira prova de paciência e superação para as vítimas da doença. Durante um período significativo, são realizadas incontáveis tentativas para estabelecer o diagnóstico, tornando-se um alívio quando concretizado. A sensação de busca infinita cessa, dando lugar ao consolo de que, apesar de ser uma doença incurável, há tratamento e não é maligna ${ }^{24}$.

Ao recordar-se do alívio que foi receber a notícia do diagnóstico e o quão doloroso foi seu sofrimento com a reação da sociedade, Íris expressa:

"Depois que eu tive a certeza da doença, se tornou muito mais fácil. É muito mais fácil você lidar com uma coisa que você sabe com o que você não sabe. Já sei pra onde seguir. A minha própria família... achava que eu tinha provocado. Que eu tinha provocado o aborto. Só podia ser. Meu sofrimento maior é a incompreensão das pessoas que cercam a gente, porque elas não entendem." (Íris)

A respeito, Begônia disse:

“(...) fiquei com depressão duas vezes, devido a ninguém acreditar em mim, comecei a me isolar. Só quem acredita é ele (refere-se ao esposo) porque já sabe, que convive, e meus filhos, mas ou outros não, até meus vizinhos não acreditam, Até os médicos achavam que eu era louca, antes de descobrir a endometriose." (Begônia)

Muitas mulheres como Irís e Begônia são apontadas como "loucas" por aqueles que com elas convivem devido à dificuldade encontrada pelos médicos em realizar o diagnóstico. Os sintomas estão ali presentes, mas não há como prová- $\operatorname{los}^{24}$.

Segundo os dados coletados, a maior dificuldade encontrada para conviver com a endometriose foi a dor. Rosa e Gardênia contam expressando a insatisfação, o incômodo e o desconforto: 
"Quando não estou menstruada convivo normalmente. Mas uns 5 dias antes... sinto muita dor. Durante, uma dor maior ainda. Sinto ânsia de vômito, diarreia, dor de cabeça, e muito mal estar. Esse período eu tenho que ficar em casa. Porque é da cama pro banheiro..." (Rosa)

"É até meio gozado. Porque meu marido fala assim: Ave Maria, quando você fica perto de menstruar você já fica em pânico. Eu já morro de medo. Já fico nervosa, apreensiva, só medo de ter que bater na emergência. Eu sinto muitas dores, diarreia, vômito... eu desmaio. São dores insuportáveis. Sinto dores também durante a relação sexual." (Gardênia)

Entretanto, a dor não é o único fator que influencia na vida dessas mulheres. Os sintomas depressivos incluem dificuldade no relacionamento conjugal e familiar, diminuição de atividades e interação social e prejuízo no desempenho profissional ${ }^{25}$. A respeito dessas relações sociais, emocionadas e decepcionadas com as próprias atitudes, Hortênsia e Acácia expressaram seus mais profundos sentimentos.

"Ah...muito ruim porque até a gente conviver com os filhos, com o marido. Paciência, a agente tica irritada, muito irritada. E... (Pausa) Às vezes a gente fala coisas que não deve. Muitas vezes peço desculpa pros meus filhos. Às vezes eu não quero nem ouvir nem a voz deles perto de mim. Muitas vezes deixei de ir pra algum lugar pra me divertir, até de ir pra igreja. A gente sair com dor não dá." (Hortênsia)

"Durante a minha vida sexual, com meu marido, já me criou problemas, a ponto de eu querer até me separar dele, porque são muitas dores, e as vezes as pessoas não entendem." (Acácia)

Quanto à dor, diversas pesquisas investigaram o binômio deste sintoma com endometriose. Em estudo ${ }^{26}$ realizado com 115 mulheres com endometriose e dor pélvica crônica, avaliando dor, qualidade de vida e os fatores psicossociais que incluíam o estilo de enfrentamento catastrófico. A catastrofização é uma distorção cognitiva onde se antecipa o futuro sempre de forma pessimista. Os resultados dessa pesquisa sugeriram que fatores de ordem biopsicossocial, especificamente a catastrofização, relacionavam-se fortemente com experiência da dor em mulheres com endometriose.

Outro estudo evidenciou associação entre intensidade da dor e depressão, sendo que entre mulheres com depressão moderada ou grave, $91,7 \%(p<0,001)$ tinham dismenorreia severa e $61,1 \%(p<0,001)$ dor pélvica crônica severa. A intensidade dos sintomas dolorosos também se associou com a presença e intensidade de estresse ${ }^{25}$.
O papel da infertilidade é examinado como um fator de piora do estado emocional e da Saúde Mental. É válida a ressalva de que a infertilidade causada pela endometriose não afeta somente os aspectos psicológicos da paciente, mas também de seus parceiros. A procriação de descendentes faz parte da naturalidade dos seres vivos e da cultura ocidental. Portanto, as pessoas não estão psicologicamente preparadas para fugir do padrão. A incompreensão e falta de companheirismo diante desta situação sobrecarrega o casamento e em alguns casos torna-se motivo de divórcio $^{27}$.

A maioria das mulheres demonstrou o intenso desejo em procriar, característico do ser humano, e as dificuldades para isso. Entretanto, transpareceram a satisfação de dispor da compreensão e apoio de seus companheiros perante a doença e a dificuldade de ter filhos, como fizeram Flor-delis, Íris e Angélica:

"Meu filho que é o que eu mais quero. Meu marido quer ter, ele tem vontade, de ter um filho. Eu não posso dar. Aí ele fica me cobrando. Uma coisa que eu não posso dar. Isso te afeta no sentimental, psicológico." (Flor-de-lis)

"Eu teria os 3 filhos que eu perdi. Ainda bem que no meu caso eu tenho um companheiro muito compreensível. Eu sinto que ele tem vontade também. Mas sempre diz assim: que a gente deve seguir o que Deus deu pra gente. E sempre ele diz, que tenho que me preocupar com o meu bem estar, com a minha saúde." (Íris)

"Tenho vontade de ter filhos. Mas se for a vontade de Deus, vai ter. Ele (refere-se ao esposo) tem muita vontade. O desejo de homem quando casa é ter um filho, fazer a família. Mas graças a Deus que eu não tenho dificuldade com meu marido. Ele me entende, gente fica triste, mas o que a gente pode fazer se aconteceu." (Angélica)

A vida é um ciclo que está em constante mudança. Crescemos com a missão de nos adequarmos a este ciclo. Entretanto, na maioria das vezes, as mudanças não possuem uma boa aceitação de imediato, ainda mais quando, através delas, a vida perde a qualidade preconizada. Qualidade de vida é a percepção do indivíduo sobre sua posição na vida, o estado em que se encontra, seus comportamentos, capacidades e sua satisfação ou insatisfação em relação a isso. O termo está vinculado à saúde, levando-se em consideração os âmbitos físico, social e psicológico ${ }^{28}$.

As mulheres que participaram desta pesquisa analisaram as mudanças que ocorreram em suas vidas, mesmo que indiretamente, e, esperançosas, demonstraram suas 
expectativas, imaginando como seriam suas vidas sem a doença. A maioria absoluta relatou que a endometriose só trouxe desvantagens às suas vidas através de lamentações e algumas vezes de lágrimas.

“(...) é um vazio que eu sinto. Um vazio que eu não sei em que momento vai ter solução. Seria bem melhor né se eu não tivesse isso. Seria bom. Porque eu não ia me sentir com esse incômodo, sentir dores. (Pausa) la me sentir uma mulher, uma mulher feliz. Mais realizada como pessoa." (Margarida)

"Mudou no sentido pessoal, afetivo. Eu teria que ter algum filho. Devo evitar a cirurgia pra retirada do útero pra isso... A vida seria bem mais fácil. Sempre um problema de saúde tira um pouco da paz da gente. Querendo ou não preocupa." (Violeta)

"Desde que eu tive meu filho, fui procurar trabalhar eu não consegui porque eu sentia muita dor. Eu fazia todo tipo de trabalho pesado. A minha casa ultimamente, parece um lixão. Não tenho nem coragem de limpar. Meu psicológico tá muito louco. Eu já não aguento mais. Eu já falei pro meu médico que não quero mais nem viver. A relação sexual...uma porcaria. Eu fico assim... me sentindo mal entendeu? Tu tem uma vida normal aí de repente muda." (Begônia)

Estes resultados corroboram com os achados de outras pesquisas que evidenciaram diminuição da qualidade de vida, alteração do humor e prejuízo no convívio e suas relações pessoais e profissionais ${ }^{7,29}$.

A dor crônica pode implicar em frustração, disfunção social e dificuldades no trabalho. A infertilidade causada pela endometriose, assim como o atraso no diagnóstico, também pode levar à frustração e ao isolamento. Os efeitos negativos da endometriose na relação sexual podem perturbar as relações familiares. Portanto, a endometriose tem uma carga psicológica grave, ameaçando a saúde mental de forma que intervenções psicológicas devem ser sugeridas para as pacientes com prejuízo psicossocial ${ }^{3,7,29}$.

Vale salientar que as intervenções medicamentosas e cirúrgicas, frustradas ou não, e a permanência dos sintomas dolorosos são agravantes para a redução da qualidade de vida.

\section{CONSIDERAÇÕES FINAIS}

Com base nos dados obtidos, é possível afirmar que as mulheres portadoras de endometriose ouvidas nesta pesquisa, em sua maioria, não conhecem a doença com a qual convivem e percebem as mudanças advindas da doença de forma negativa. De acordo com a vivência e o contexto social em que estão inseridas, é que estas formulam suas opiniões. Que se resumem em: A endometriose diminui sim a qualidade de suas vidas.

Os relatos que evidenciaram o isolamento social consequente da dor e os problemas de relacionamento familiar, profissional e de amizade, provenientes das alterações dos aspectos psicológicos corroboram o crescimento de aspectos negativos da qualidade de vida no pós-diagnóstico. A partir dos relatos, emergiu a importância do profissional de saúde no fornecimento de informações de qualidade a fim de propiciar o empoderamento destas mulheres, uma vez que conhecer melhor a patologia que lhes aflige é fundamental para a adesão ao tratamento e a busca de alternativas que melhorem aspectos biopsicossociais.

A generalização é uma limitação desta pesquisa, uma vez que estes resultados são válidos para a população que se escolheu estudar, mas podem não refletir o que se passa com as demais mulheres que convivem com endometriose. Contudo, apesar de não refletir a realidade ou o universo de mulheres com endometriose, permite suscitar hipóteses para pesquisas seguintes. Faz-se necessário assistir as mulheres que convivem com a endometriose de maneira holística, pois seus sintomas afetam a paciente em níveis físicos e emocionais, como as participantes desse estudo relataram.

Acredita-se que este trabalho contribui à medida que traz a percepção de mulheres acerca da endometriose e de sua qualidade de vida pós-diagnóstico, permitindo aos profissionais conhecer como essas mulheres compreendem a doença e os aspectos modificados em sua qualidade de vida, proporcionando a estas uma assistência de acordo com suas necessidades e expectativas.

\section{REFERÊNCIAS}

1. Fuldeore MJ, Soliman AM, Prevalence and symptomatic burden of diagnosed endometriosis in the United States: national estimates from a cross-sectional survey of 59,411 women. Gynecol Obstet Invest. 2017;82(5):453-61. https://doi.org/10.1159/000452660

2. Dunselman GA, Vermeulen N, Becker C, Calhaz-Jorge C, D'Hooghe T, De Bie B, Heikinheimo O, Horne AW, ,Kiesel L, Nap A, Prentice A, Saridogan E, Soriano D, Nelen W. ESHRE guideline: management of women with endometriosis. Hum Reprod. 2014;29(3):400-12. https://doi.org/10.1093/humrep/det457

3. Chaman-Ara K, Bahrami MA, Moosazadeh M, Bahrami E. Quality of life in women with endometriosis: a systematic review and metaanalysis. WCRJ. 2017;4(1):e839.

4. Fourquet J, Sinaii N, Stratton P, Khayel F, Alvarez-Garriga C, Bayona $\mathrm{M}$, Ballweg ML, Flores I. Characteristics of women with endometriosis from the USA and Puerto Rico. J Endometr Pelvic Pain Disord. 2015;7(4):129-35. 
5. Bellelis P, Dias Jr JA, Podgaec S, Gonzales M, Baracat EC, Abrão MS. Aspectos epidemiológicos e clínicos da endometriose pélvica: uma série de casos. Rev Assoc Med Bras. 2010;56(4):467-71. https://doi. org/10.1590/S0104-42302010000400022

6. Flores RC, Lara EB, Corral LCQ, Chaib RAI, Pérez LO, González Díaz $\mathrm{OA}$, Flores RC. Quality of life in women with endometriosis pelvic pain treated with the levonorgestrel-releasing intrauterine system. Open J Obstet Gynecol. 2015;5:167-72. https://doi.org/10.4236/ ojog.2015.53023

7. Silva CN, Costa P, Martins C, Barat S, Alho C, Jorge CC, Osorio F. Validation of the Portuguese Version of EHP-30 (The Endometriosis Health Profile-30). Acta Med Port. 2015;28:347-56. https://doi. org/10.20344/amp.5778

8. De Graaff AA, D'Hooghe TM, Dunselman GAG, Dirksen CD, Hummelshoj L, Simoens S. The significant effect of endometriosis on physical, mental and socialwellbeing: results from an international cross-sectional survey. Hum Reprod. 2013;28(10):2677-85. https:// doi.org/10.1093/humrep/det284

9. São Bento PA, Moreira MC. Even silence has an end: informative study on endomentriosis and its signs/symptoms. J Nurs UFPE on line. 2014;8(2):457-63. https://doi.org/10.5205/reuol.4688-385831-RV.0802201429

10. Abreu R. A endometriose rouba o direito da mulher de ser Mulher! Revista PQN. 2015;11(35):49-56.

11. Silva ADR. Endometriose e Infertilidade: o papel do tratamento cirúrgico pélvico a ciclos de procriação medicamente assistida [dissertação]. Porto: Universidade do Porto; 2012.

12. Moradi M, Parker M, Sneddon A, Lopez V, Ellwood D. Impact of endometriosis on women's lives: a qualitative study. BMC Womens Health. 2014;14:123. https://doi.org/10.1186/1472-6874-14-123

13. Bardin L. Análise de conteúdo. Lisboa: Edições 70; 2009.

14. Minson FP, Abrão MS, Sardá Júnior J, Kraychete DC, Podgaec S, Assis FD. Importância da avaliação da qualidade de vida em pacientes com endometriose. Rev Bras Ginecol Obstet. 2012:34(1):11-5.

15. Podgaec S. Manual de endometriose. São Paulo: FEBRASGO; 2014.

16. Santos TM, Pereira AM, Lopes RG, Depes DB. Tempo transcorrido entre o início dos sintomas e o diagnóstico de endometriose. Einstein. 2012;10(1):39-43. https://doi.org/10.1590/S167945082012000100009

17. Aguiar A, Capela E, Caramelo O, Costa AR, Ferreira J, Guerra A, Marques AL, Relvas A, Jorge CC. Endometriose: recomendações de consenso nacionais- clínica e diagnóstico. Acta Obstet Ginecol Port. 2016;10(2):162-72.
18. Carvalho MJ, Barbosa A, Couto D, Geraldes F, Vilhena I, Reis JL, Damasceno J, Figueiredo S, Águas F. Endometriose: recomendações de consenso nacionais - tratamento médico. Acta Obstet Ginecol Port. 2016;10(3):257-67.

19. Brasil (BR). Constituição da República Federativa do Brasil de 1988. Brasília, DF: Senado Federal: Centro Gráfico; 1988.

20. Brasil (BR). Lei no 8.080, de 19 de setembro de 1990 [Internet]. 1990 [capturado 2013 Dez 19]. Disponível em: http://www. planalto.gov.br/ccivil_03/leis/l8080.htm

21. Cunha ACO. O direito à informação em saúde do paciente do sistema único de saúde- SUS no Rio Grande do Sul [projeto de pesquisa]. Porto Alegre: FIOCRUZ; 2012.

22. Romão APMS. O impacto da ansiedade e depressão na qualidade de vida de mulheres com dor pélvica crônica [dissertação]. Ribeirão Preto: USP; 2008.

23. Rodrigues PSC, Silva TASM, Souza MMT. Endometriose importância do diagnóstico precoce e atuação da enfermagem para o desfecho do tratamento. Rev Pró-UniverSUS. 2015;6(1): $13-6$.

24. Barbosa DAS, Oliveira AM. Endometriose e seu impacto na fertilidade feminina. Saúde Ciênc Ação. 2015;1(1):43-56.

25. Donatti L, Ramos DG, Andres MP, Passman LJ, Podgaec S. Pacientes com endometriose que utilizam estratégias positivas de enfrentamento apresentam menos depressão, estresse e dor pélvica. Einstein. 2017;15(1):65-70. https://doi.org/10.1590/s167945082017 ao3911

26. Martin $\mathrm{CE}$, Johnson $\mathrm{E}$, Wechter ME, Leserman J, Zolnoun DA. Catastrofização: um preditor de dor persistente entre mulheres com endometriose em 1 ano. Hum Reprod. 2011;26(11):3078-84. https://doi.org/10.1093/humrep/der292

27. Sekula VG. Impacto do tratamento cirúrgico laparoscópico na qualidade de vida de mulheres portadoras de endometriose profunda [dissertação]. São Paulo: Faculdade de Ciências Médicas da Santa Casa de São Paulo; 2010.

28. Silva MPC, Marqui ABT. Qualidade de vida em pacientes com endometriose: um estudo de revisão. Rev Bras Promoç Saúde, 2014;7(3):413-21.

29. Facchin F, Barbara G, Saita E, Mosconi P, Roberto A, Fedele L, Vercellini P. Impact of endometriosis on quality of life and mental health: pelvic pain makes the difference. J Psychosom Obstet Gynaecol. 2015;36(4):135-41. https://doi.org/10.3109/016748 2X.2015.1074173 